Article

\title{
Structure-Activity Relationships of Acyclic Selenopurine Nucleosides as Antiviral Agents
}

\author{
Pramod K. Sahu ${ }^{\dagger}$, Tamima Umme ${ }^{\dagger}$, Jinha Yu, Gyudong Kim, Shuhao Qu, Siddhi D. Naik \\ and Lak Shin Jeong *
}

Research Institute of Pharmaceutical Sciences, College of Pharmacy, Seoul National University, Seoul 08826, Korea; pramodksahu@gmail.com (P.K.S.); jhini19@gmail.com (T.U.); jinha.yu@nih.gov (J.Y.); gdkim0217@gmail.com (G.K.); shuhaoqus@gmail.com (S.Q.); siddhinaik40@gmail.com (S.D.N.)

* Correspondence: lakjeong@snu.ac.kr; Tel.: +82-2-880-7850

+ The authors contributed equally to this work.

Academic Editor: Zhenjun Yang

Received: 17 June 2017; Accepted: 10 July 2017; Published: 12 July 2017

\begin{abstract}
A series of acyclic selenopurine nucleosides $\mathbf{3 a}-\mathbf{f}$ and $\mathbf{4 a}-\mathbf{g}$ were synthesized based on the bioisosteric rationale between oxygen and selenium, and then evaluated for antiviral activity. Among the compounds tested, seleno-acyclovir (4a) exhibited the most potent anti-herpes simplex virus (HSV)-1 $\left(\mathrm{EC}_{50}=1.47 \mu \mathrm{M}\right)$ and HSV-2 $\left(\mathrm{EC}_{50}=6.34 \mu \mathrm{M}\right)$ activities without cytotoxicity up to $100 \mu \mathrm{M}$, while 2,6-diaminopurine derivatives $4 \mathbf{e}-\mathrm{g}$ exhibited significant anti-human cytomegalovirus (HCMV) activity, which is slightly more potent than the guanine derivative $4 \mathbf{d}$, indicating that they might act as prodrugs of seleno-ganciclovir (4d).
\end{abstract}

Keywords: antiviral; acyclic selenopurine nucleoside; prodrug; anti-herpetic

\section{Introduction}

Modified nucleosides have continued to be fruitful resources for the development of antiviral agents [1]. Among these, acyclic nucleosides have been clinically used as drugs of choice for the treatment of herpetic viral infections such as herpes simplex virus (HSV), varicella-zoster virus (VZV), and human cytomegalovirus (HCMV) [2]. For example, acyclovir (1) [3,4] is widely used for the treatments of HSV- and VZV-infected patients, while ganciclovir (2) $[5,6]$ is clinically used for the treatment of HCMV infections (Figure 1).

Compound $\mathbf{1}$ is intracellularly phosphorylated by viral-encoded thymidine kinase to its monophosphate, which is further phosphorylated to its triphosphate by cellular kinases. This triphosphate inhibits viral DNA polymerase reversibly by competing with the natural substrate, 2'-deoxyguanosine-5'-triphosphate (dGTP), and/or being incorporated into viral DNA chains, resulting in viral DNA chain termination [7,8]. On the other hand, compound $\mathbf{2}$ is also converted to its monophosphate by viral-encoded kinase (phosphotransferase), which is then subsequently converted into the triphosphate by cellular kinase [9]. This triphosphate inhibits HCMV DNA polymerase with a mechanism of action similar to $\mathbf{1}$ [9]. However, these drugs $\mathbf{1}$ and $\mathbf{2}$ have exhibited drawbacks such as hepatotoxicity [10], poor water solubility, and the appearance of resistant strains [11]. Although their poor water solubility has been solved by the amino acid ester prodrug approach, hepatotoxicity and resistance problems should still be solved. Thus, it has been highly desirable to develop new antiviral agents to tackle these problems.

In preliminary accounts, we synthesized the selenium analogues $3\left(X=H, R_{1}=O H, R_{2}=N_{2}\right.$, seleno-acyclovir) and $4\left(\mathrm{X}=\mathrm{CH}_{2} \mathrm{OH}, \mathrm{R}_{1}=\mathrm{OH}, \mathrm{R}_{2}=\mathrm{NH}_{2}\right.$, seleno-ganciclovir $)$ of $\mathbf{1}$ and 2 because they are in bioisosteric relationships; we also evaluated them for antiviral activity [12]. As expected, seleno-acyclovir exhibited potent anti-HSV activity, while seleno-ganciclovir exerted significant 
anti-HCMV activity [11]. Thus, based on these findings, it was very interesting to carry out the structure-activity relationship (SAR) study modifying the C2 and/or C6 positions of the guanine base of seleno-acyclovir and seleno-ganciclovir, which might overcome the drawbacks such as high cytotoxicity and poor water solubility caused by the guanine base. Herein, we report the full accounts of acyclic selenopurine nucleosides 3 and 4 modified at the C2 and/or C6 position as antiviral agents.<smiles>[X]C(CO)OCn1cnc2c(=O)[nH]c(N)nc21</smiles>

$1(\mathrm{X}=\mathrm{H}$, acyclovir)

$2\left(\mathrm{X}=\mathrm{CH}_{2} \mathrm{OH}\right.$, ganciclovir $)$

Structure-Activity Relationship (SAR)

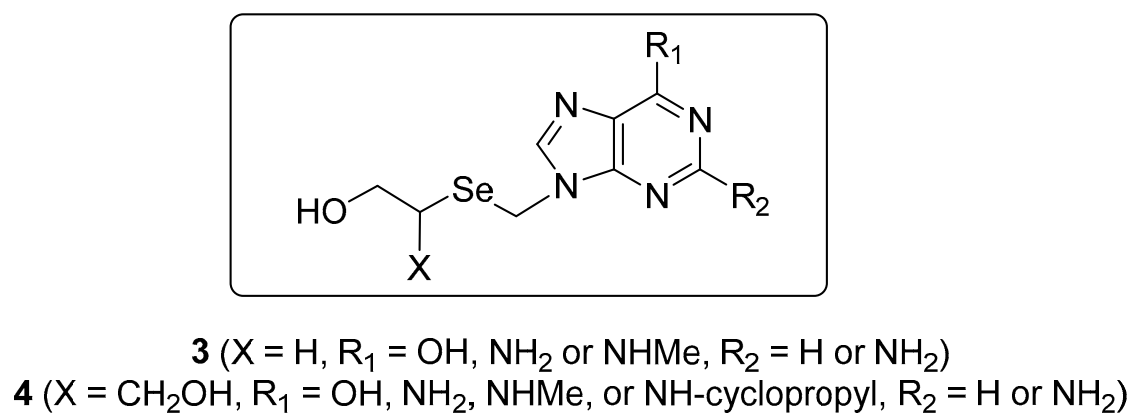

Figure 1. The rationale for the design of acyclic selenopurine nucleosides 3 and 4 based on the potent antiviral activity of $\mathbf{1}$ and 2 .

\section{Results and Discussion}

\subsection{Chemistry}

Scheme 1 illustrates the synthesis of 6-chloro- and 2-amino-6-chloropurine derivatives 11 and 12, which serve as the versatile intermediates for the synthesis of various seleno-acyclovir analogues [11]. 2-Bromoethanol (5) was converted to the glycosyl donor 8 according to our previously reported procedure [12]. 2-Bromoethanol (5) was treated with selenium dianion prepared in situ by heating with selenium powder and hydrazine hydrate in aqueous $\mathrm{KOH}$ solution to afford the diselenide $\mathbf{6}$, which was protected with the tert-butyldiphenylsilyl (TBDPS) group to give 7. Treatment of 7 with $\mathrm{NaBH}_{4}$ followed by trapping with methylene bromide yielded the glycosyl donor 8. Condensation of 8 with 6-chloropurine and 2-amino-6-chloropurine in the presence of $\mathrm{K}_{2} \mathrm{CO}_{3}$ produced the desired $N^{9}$-6-chloropurine derivative 9 and $N^{9}$-2-amino-6-chloropurine derivative 10, respectively, along with concomitant formations of the corresponding $\mathrm{N}^{7}$-isomers in negligible amounts. The $N^{9}$-isomers were confirmed by the chemical shift of the C5 signal of ${ }^{13} \mathrm{C}-\mathrm{NMR}$. The pronounced difference in $N^{7}-$ and $N^{9}$-isomers reside in the C5 signals of ${ }^{13}$ C-NMR [13]. In general, the C5 signal ( 132 ppm) in the $N^{9}$-isomer is shifted downfield by $\sim 10$ ppm relative to the corresponding shift in the $N^{7}$-isomer [13]. The chemical shift of the C5 in 9 was 131.69 ppm, indicating that it is a $N^{9}$-isomer. The $N^{9}$-isomer 9 was further confirmed after being converted to the final 4a. Removals of the TBDPS group in 9 and 10 with $\mathrm{n}-\mathrm{Bu}_{4} \mathrm{NF}$ afforded the key intermediates 11 and 12, respectively. 


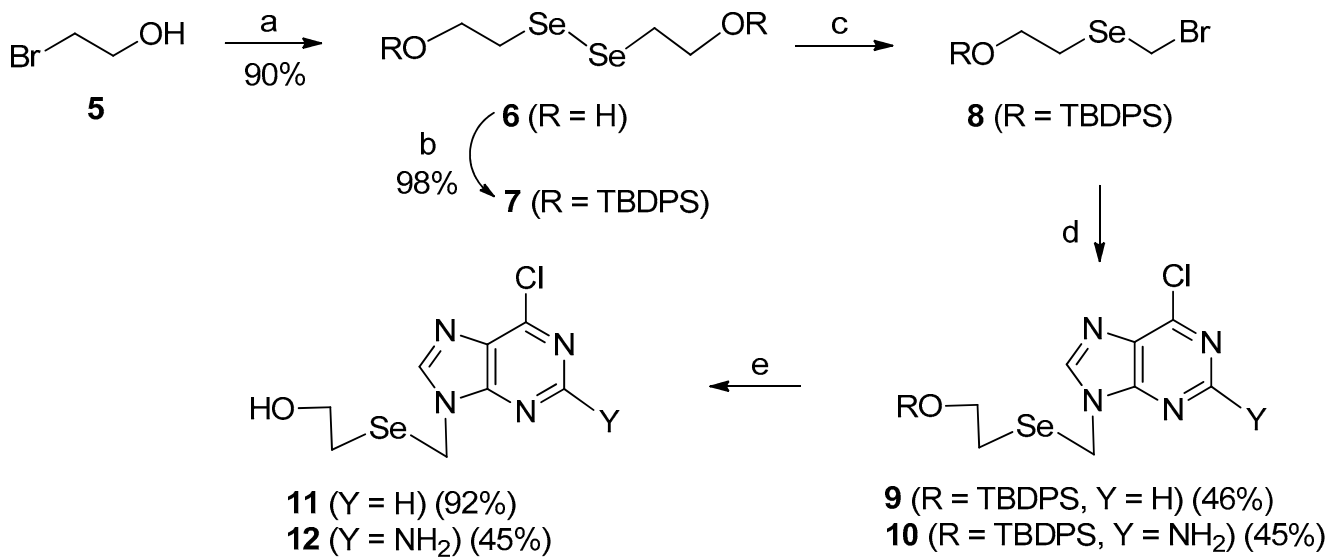

Reagents and conditions: (a) Se, $\mathrm{NH}_{2} \mathrm{NH}_{2}-\mathrm{H}_{2} \mathrm{O}, \mathrm{KOH}, \mathrm{H}_{2} \mathrm{O}, 80^{\circ} \mathrm{C}-55^{\circ} \mathrm{C}, 15 \mathrm{~h}$; (b) TBDPSCl, TEA, DMF, $\mathrm{CH}_{2} \mathrm{Cl}_{2}$, DMAP, rt, $8 \mathrm{~h}$; (c) $\mathrm{NaBH}_{4}, \mathrm{CH}_{2} \mathrm{Br}_{2}$, EtOH, $0^{\circ} \mathrm{C}-\mathrm{rt}, 2 \mathrm{~h}$; (d) $\mathrm{K}_{2} \mathrm{CO}_{3}$, 18-crown-6, 6-chloropurine or 2-amino-6-chloropurine, $85^{\circ} \mathrm{C}-55^{\circ} \mathrm{C}, 12 \mathrm{~h}$; (e) $n$-Bu $4 \mathrm{NF}$, THF, rt, $5 \mathrm{~h}$.

Scheme 1. Synthesis of 6-chloro- and 2-amino-6-chloropurine derivatives 11 and 12.

Conversion of the key intermediates $\mathbf{1 1}$ and $\mathbf{1 2}$ into the seleno-acyclovir analogues $\mathbf{3 a}-\mathbf{c}$ and $\mathbf{4 a - c}$ is shown in Scheme 2. Treatment of $\mathbf{1 1}$ and $\mathbf{1 2}$ with 2-mercaptoethanol and $\mathrm{NaOMe}$ in $\mathrm{MeOH}$ yielded seleno-inosine derivative $3 \mathbf{3}(80 \%)$ and seleno-acyclovir 4a [12] (94\%), respectively. The $N^{9}$-isomer 4a was further confirmed by comparing the C5 signal ( $\delta 116.73 \mathrm{ppm})$ of 4a with that ( $\delta 116.73 \mathrm{ppm})$ of acyclovir (1) [12]. Compounds 11 and 12 were also converted to the $N^{6}$-methyladenine derivative $3 \mathbf{b}$ and the 2 -amino- $N^{6}$-methyladenine derivative $4 \mathbf{b}$, respectively, by heating with $40 \%$ aqueous methylamine solution in $\mathrm{MeOH}$. To overcome the low water solubility of the hypoxanthine or guanine base, $\mathbf{1 1}$ and $\mathbf{1 2}$ were transformed to the adenine derivative $3 \mathrm{c}$ and 2,6-diamino derivative $\mathbf{4 c}$, respectively, by heating with $t$-butanolic ammonia at $85^{\circ} \mathrm{C}$.

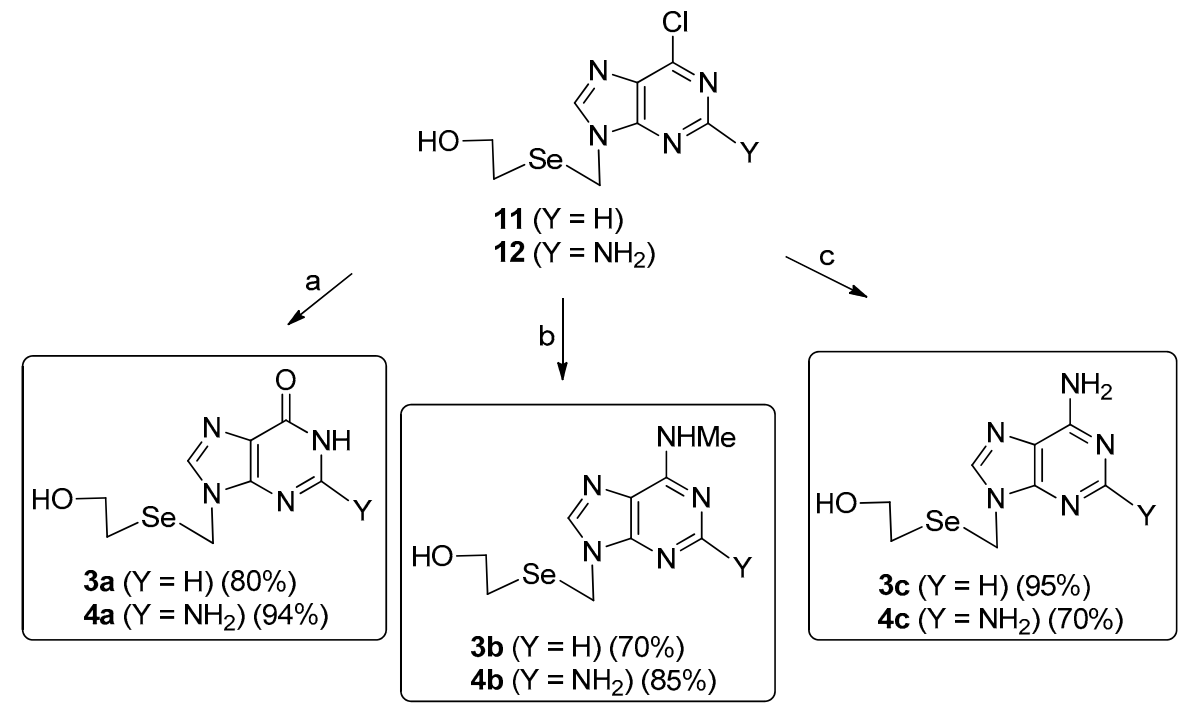

Reagents and conditions: (a) 2-mercaptoethanol, $\mathrm{NaOMe}, \mathrm{MeOH}, 75^{\circ} \mathrm{C}, 2 \mathrm{~d}$; (b) $40 \%$ aqueous $\mathrm{CH}_{3} \mathrm{NH}_{2}, \mathrm{MeOH}, 85^{\circ} \mathrm{C}, 10 \mathrm{~h}$; (c) $\mathrm{NH}_{3}$ in $t$-butanol, $85^{\circ} \mathrm{C}, 12 \mathrm{~h}$.

Scheme 2. Synthesis of seleno-acyclovir analogues 3a-c and $4 a-c$.

For the synthesis of seleno-ganciclovir analogues, the key intermediates 6-chloropurine derivative 20 and 2-amino-6-chloropurine derivative 21 were first synthesized, starting from glycerol (13), as 
depicted in Scheme 3 [12]. Glycerol (13) was converted to the glycosyl donor 17 according to our previously reported procedure [12]. Glycerol (13) was protected with the 1,3-benzylidene group by treating with benzaldehyde in the presence of $p-\mathrm{TsOH}$ to give 14, which was treated with $\mathrm{MsCl}$ to give the mesylate 15. Using similar conditions (Se, $\mathrm{NH}_{2} \mathrm{NH}_{2}-\mathrm{H}_{2} \mathrm{O}$, and $\mathrm{KOH}$ ) employed in the preparation of $\mathbf{6}$, compound $\mathbf{1 5}$ was smoothly converted to the diselenide $\mathbf{1 6}$. The reduction of diselenide 16 with $\mathrm{NaBH}_{4}$ followed by the treatment with $\mathrm{CH}_{2} \mathrm{Br}_{2}$ yielded the glycosyl donor 17 . Without purification, compound $\mathbf{1 7}$ was condensed with 6-chloropurine and 2-amino-6-chloropurine using the same procedure employed in the preparation of 9 and 10 to afford 18 and 19, respectively. The removal of 1,3-benzylidene in $\mathbf{1 8}$ and $\mathbf{1 9}$ was achieved by treating with iodine in $\mathrm{MeOH}$ to give $\mathbf{2 0}$ and 21 , respectively.

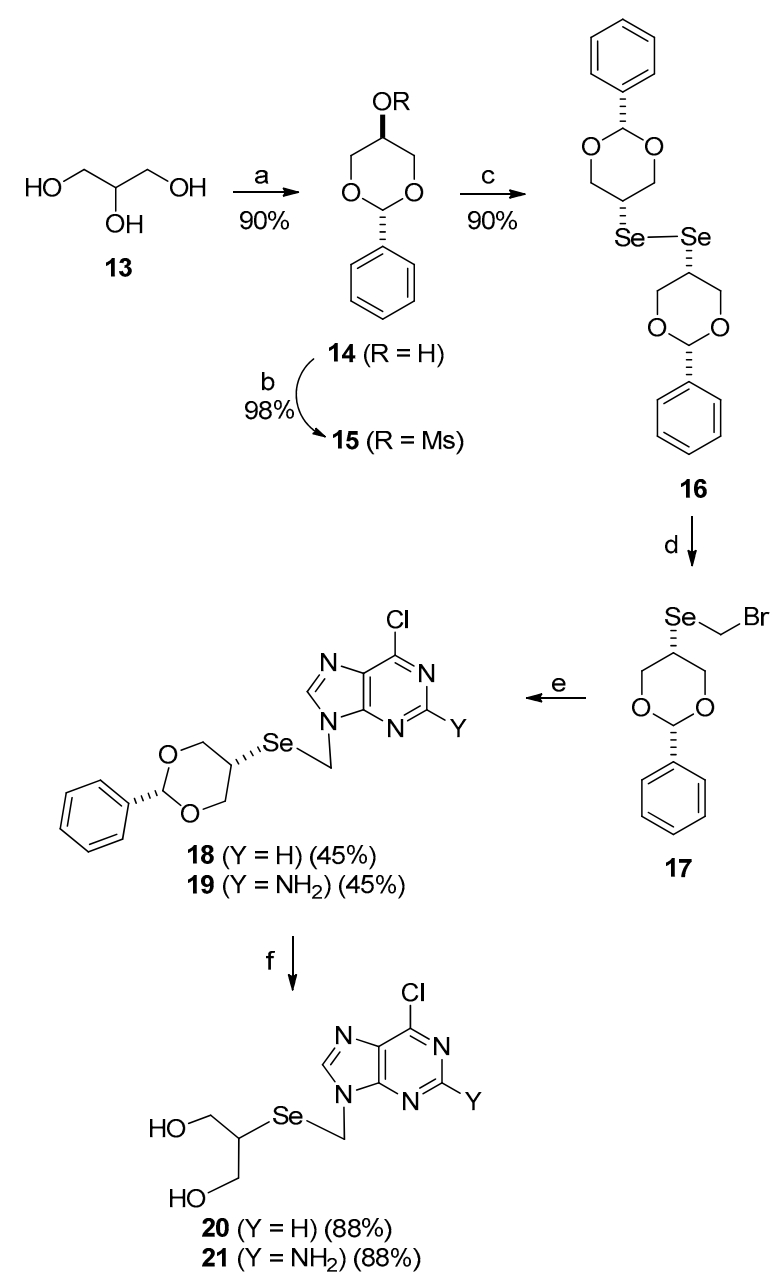

Reagents and conditions: (a) $\mathrm{PhCHO}, p-\mathrm{TsOH}, \mathrm{C}_{6} \mathrm{H}_{6} / \mathrm{Hx}(1 / 1), 85^{\circ} \mathrm{C}$,
$15 \mathrm{~h}$; (b) $\mathrm{MsCl}$, pyridine, $0^{\circ} \mathrm{C}$ to rt, $1 \mathrm{~h}$; (c) $\mathrm{Se}, \mathrm{NH}_{2} \mathrm{NH}_{2}-\mathrm{H}_{2} \mathrm{O}, \mathrm{KOH}, \mathrm{H}_{2} \mathrm{O}$,
$85^{\circ} \mathrm{C}, 2 \mathrm{~h}$; (d) i) $\mathrm{NaBH}_{4}, \mathrm{EtOH}, 0^{\circ} \mathrm{C}, 10$ min, ii) $\mathrm{CH}_{2} \mathrm{Br}_{2}, \mathrm{EtOH}, \mathrm{rt}, 1 \mathrm{~h}$, iii)
$\mathrm{CH}_{2} \mathrm{Br}_{2}$, EtOH, rt, $1 \mathrm{~h}$; (e) $\mathrm{K}_{2} \mathrm{CO}_{3}, 18-\mathrm{crown}-6,2-\mathrm{amino}-6-c h l o r o p u r i n e$
DMF, $85^{\circ} \mathrm{C}-55^{\circ} \mathrm{C}, 12 \mathrm{~h}$; (f) $\mathrm{I}_{2}, \mathrm{MeOH}, 70^{\circ} \mathrm{C}, 3 \mathrm{~h}$.

Scheme 3. Synthesis of key intermediates 6-chloropurine derivative 20 and 2-amino-6-chloropurine derivative 21 starting from glycerol (13).

The key intermediates $\mathbf{2 0}$ and $\mathbf{2 1}$ were converted to the seleno-ganciclovir analogues $\mathbf{3 d}-\mathbf{f}$ and $\mathbf{4 d - g}$, as shown in Scheme 4. Treatment of $\mathbf{2 0}$ and $\mathbf{2 1}$ with 2-mercaptoethanol and $\mathrm{NaOMe}$ afforded the seleno-inosine derivative $\mathbf{3 d}$ and the seleno-ganciclovir $4 \mathbf{d}$ [12], respectively. The $N^{9}$ regiochemistry of $4 \mathbf{d}$ was further confirmed by comparing the $C 5$ signal ( $\delta 116.56 \mathrm{ppm}$ ) of 
4d with that ( $\delta 116.40 \mathrm{ppm}$ ) of ganciclovir (2) [12]. The 6-chlororpurine derivative 20 was converted to the $N^{6}$-methyladenine derivative $3 \mathbf{e}$ and the adenine derivative $3 \mathbf{f}$ by treating with methylamine and ammonia, respectively. The 2-amino-6-chloropurine derivative 21 was treated with methylamine, ammonia, and cyclopropylamine to afford the 2-amino- $N^{6}$-methylaminopurine derivative $4 \mathbf{e}$, the 2,6-diaminopurine derivative $4 \mathbf{f}$, and the 2-amino- $N^{6}$-cyclopropylaminopurine derivative $4 \mathbf{g}$, respectively.

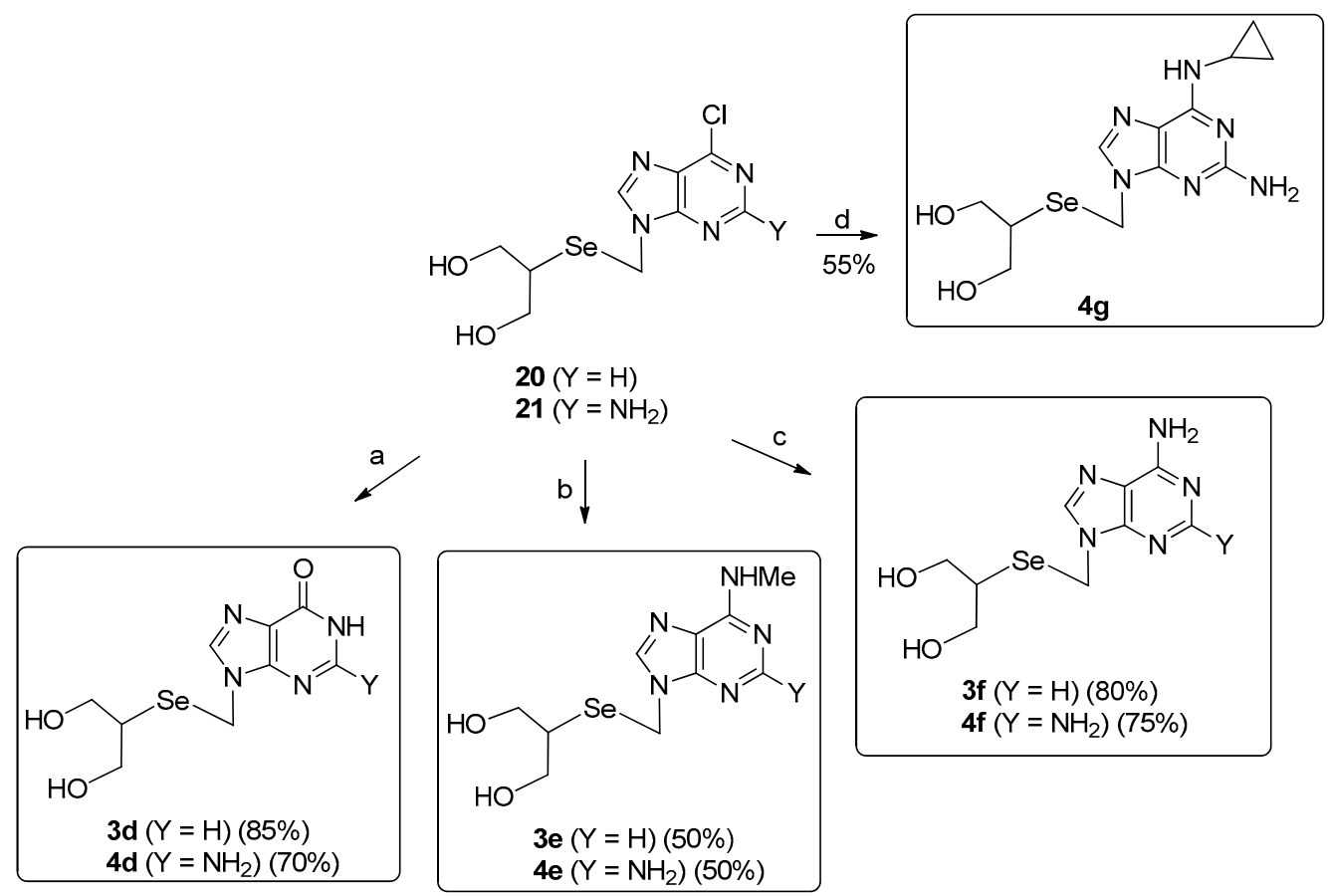

Reagents and conditions: (a) 2-mercaptoethanol, $\mathrm{NaOMe}, \mathrm{MeOH}, 75^{\circ} \mathrm{C}, 4 \mathrm{~d}$; (b) $40 \%$ aqueous $\mathrm{CH}_{3} \mathrm{NH}_{2}$, $\mathrm{MeOH}, 85^{\circ} \mathrm{C}, 48 \mathrm{~h}$; (c) $\mathrm{NH}_{3}$ in $t$-butanol, $85^{\circ} \mathrm{C}, 12 \mathrm{~h}$; (d) cyclopropanamine, $\mathrm{Et}_{3} \mathrm{~N}, \mathrm{EtOH}, 10{ }^{\circ} \mathrm{C}, 48 \mathrm{~h}$.

Scheme 4. Synthesis of seleno-ganciclovir analogues $3 \mathbf{d}-\mathbf{f}$ and $\mathbf{4 d - f}$.

\subsection{Antiviral Activity}

All the final compounds $\mathbf{3 a}-\mathbf{f}$ and $\mathbf{4 a}-\mathbf{g}$ were assayed for their antiviral activity against several herpes viruses such as HSV-1 (strain F, VR-733), HSV-2 (strain MS, VR-540), VZV (Ellen, VR-1367), and HCMV (Davis, VR-807) [12,14]. Cytotoxicity data were measured in HEL299 (CCL-137) cells as described previously $[12,14]$. As shown in Table 1, compound 4a exhibited the most potent anti-HSV-1 and HSV-2 activities, whereas compound $4 \mathbf{e}$ exerted the most potent antiviral activity against HCMV, although it is moderate. It is interesting to note that 2,6-disubstituted nucleosides exhibited antiviral activity, but 6-substituted nucleosides were totally inactive up to $100 \mu \mathrm{M}$, regardless of the substitution at the $X$. Compounds $\mathbf{4 b}$ and $4 \mathbf{c}$ also exhibited significant antiviral activities against HSV-1 and HSV-2, indicating that they might be deaminated by the cellular nucleoside deaminase to serve as prodrugs of seleno-acyclovir (4a), although this should be confirmed by an adenosine deaminase test. Similarly, compounds $4 \mathbf{e}-\mathbf{g}$, which seem to act as prodrugs of seleno-ganciclovir (4d), also exhibited significant anti-HCMV activity and they were more potent than the parent compound 4d. However, all compounds were neither active nor toxic up to $100 \mu \mathrm{M}$ against VZV. The finding that all synthesized compounds were less potent than the reference compounds $\mathbf{1}$ and $\mathbf{2}$ might be explained by the difficulty in phosphorylation induced by steric effects of the bulky selenium atom, although it was much relieved by the freely rotatable acyclic single bond [15]. 
Table 1. Antiviral activities of all the final nucleosides 3a-f and 4a-g.

\begin{tabular}{|c|c|c|c|c|c|}
\hline \multirow{2}{*}{ Compound $\left(X, R_{1}, R_{2}\right)$} & \multicolumn{4}{|c|}{$\mathrm{EC}_{50}(\mu \mathrm{M})^{\mathrm{a}}$} & \multirow{2}{*}{$\begin{array}{c}\mathrm{CC}_{50}(\mu \mathrm{M})^{\mathrm{b}} \\
\text { HEL299 }\end{array}$} \\
\hline & HSV-1 & HSV-2 & VZV & HCMV & \\
\hline 3a $\left(X=H, R_{1}=O H, R_{2}=H\right)$ & $>100$ & $>100$ & $>100$ & $>100$ & $>100$ \\
\hline $3 \mathbf{b}\left(\mathrm{X}=\mathrm{H}, \mathrm{R}_{1}=\mathrm{NHMe}, \mathrm{R}_{2}=\mathrm{H}\right)$ & $>100$ & $>100$ & $>100$ & $>100$ & $>100$ \\
\hline $3 c\left(X=H, R_{1}=\mathrm{NH}_{2}, \mathrm{R}_{2}=\mathrm{H}\right)$ & $>100$ & $>100$ & $>100$ & $>100$ & $>100$ \\
\hline $3 d\left(X=\mathrm{CH}_{2} \mathrm{OH}, \mathrm{R}_{1}=\mathrm{OH}, \mathrm{R}_{2}=\mathrm{H}\right)$ & $>100$ & $>100$ & $>100$ & $>100$ & $>100$ \\
\hline $3 \mathbf{e}\left(\mathrm{X}=\mathrm{CH}_{2} \mathrm{OH}, \mathrm{R}_{1}=\mathrm{NHMe}, \mathrm{R}_{2}=\mathrm{H}\right)$ & $>100$ & $>100$ & $>100$ & $>100$ & $>100$ \\
\hline $3 f\left(X=\mathrm{CH}_{2} \mathrm{OH}, \mathrm{R}_{1}=\mathrm{NH}_{2}, \mathrm{R}_{2}=\mathrm{H}\right)$ & $>100$ & $>100$ & $>100$ & 65.2 & $>100$ \\
\hline $4 \mathbf{a}\left(\mathrm{X}=\mathrm{H}, \mathrm{R}_{1}=\mathrm{OH}, \mathrm{R}_{2}=\mathrm{NH}_{2}\right)^{\mathrm{c}}$ & 1.47 & 6.34 & $>100$ & $>100$ & $>100$ \\
\hline $4 \mathbf{b}\left(\mathrm{X}=\mathrm{H}, \mathrm{R}_{1}=\mathrm{NHMe}, \mathrm{R}_{2}=\mathrm{NH}_{2}\right)$ & 14.3 & 17.6 & $>100$ & $>100$ & $>100$ \\
\hline $4 \mathrm{c}\left(\mathrm{X}=\mathrm{H}, \mathrm{R}_{1}=\mathrm{NH}_{2}, \mathrm{R}_{2}=\mathrm{NH}_{2}\right)$ & 15.4 & 23.2 & $>100$ & $>100$ & $>100$ \\
\hline $4 \mathrm{~d}\left(\mathrm{X}=\mathrm{CH}_{2} \mathrm{OH}, \mathrm{R}_{1}=\mathrm{OH}, \mathrm{R}_{2}=\mathrm{NH}_{2}\right)^{\mathrm{c}}$ & $>100$ & $>100$ & $>100$ & 53.1 & $>100$ \\
\hline $4 \mathbf{e}\left(\mathrm{X}=\mathrm{CH}_{2} \mathrm{OH}, \mathrm{R}_{1}=\mathrm{NHMe}, \mathrm{R}_{2}=\mathrm{NH}_{2}\right)$ & $>100$ & $>100$ & $>100$ & 32.1 & $>100$ \\
\hline 4f $\left(\mathrm{X}=\mathrm{CH}_{2} \mathrm{OH}, \mathrm{R}_{1}=\mathrm{NH}_{2}, \mathrm{R}_{2}=\mathrm{NH}_{2}\right)$ & $>100$ & $>100$ & $>100$ & 34.3 & $>100$ \\
\hline $4 \mathbf{g}\left(\mathrm{X}=\mathrm{CH}_{2} \mathrm{OH}, \mathrm{R}_{1}=\right.$ NH-cyclopropyl, $\left.\mathrm{R}_{2}=\mathrm{NH}_{2}\right)$ & $>100$ & $>100$ & $>100$ & 41.1 & $>100$ \\
\hline 1 (Acyclovir) & 0.66 & 1.02 & 6.4 & 18.9 & $>100$ \\
\hline 2 (Ganciclovir) & 0.90 & 1.40 & 11.1 & 2.14 & $>100$ \\
\hline
\end{tabular}

${ }^{a}$ The effective concentration required to inhibit virus-induced cytopathic effect by $50 \%{ }^{\text {b }}$ The cytotoxic concentration of the compound responsible for $50 \%$ reduction of cell viability; ${ }^{\mathrm{c}}$ Reference [11].

\section{Materials and Methods}

Proton $\left({ }^{1} \mathrm{H}\right)$ and carbon $\left({ }^{13} \mathrm{C}\right)-N M R$ spectra were recorded on a Bruker AV 400 (Bruker Corporation, Rheinstettern, Germany) $(400 / 100 \mathrm{MHz})$ spectrometer. Chemical shifts are reported in ppm $(\delta)$ with residual solvents as the internal standard. UV spectra were recorded on a PerkinElmer Lambda25 in methanol. Melting points were determined on a Barnstead Electrothermal 9100 instrument. Mass spectra were recorded on a fast atom bombardment (FAB). All reactions involving air- or moisture-sensitive conditions were routinely carried out under an inert atmosphere of dry nitrogen. Reactions were checked by thin layer chromatography (Kieselgel 60 F254, Merck, Darmstadt, Germany). Spots were detected by viewing under UV light, and by colorizing with charring after dipping in a $p$-anisaldehyde solution. The crude compounds were purified by column chromatography on silica gel (Kieselgel 60, 230-400 mesh, Merck, Darmstadt, Germany). All solvents were purified and dried by standard techniques just before use.

\subsection{General Procedure for Base Condensation}

To a stirring solution of 7 [12] or 16 [12] (5.52 mmol) in ethanol $(25 \mathrm{~mL}), \mathrm{NaBH}_{4}(46.88 \mathrm{mmol})$ was added at $0{ }^{\circ} \mathrm{C}$, followed by the addition of a solution of $\mathrm{CH}_{2} \mathrm{Br}_{2}(683.47 \mathrm{mmol})$ in ethanol $(100 \mathrm{~mL})$. The reaction mixture was stirred at room temperature for $1 \mathrm{~h}$ and evaporated. The residue was treated with aqueous $\mathrm{NaHCO}_{3}(50 \mathrm{~mL})$ and extracted with ethyl acetate $(3 \times 150 \mathrm{~mL})$. The organic layer was dried $\left(\mathrm{MgSO}_{4}\right)$, filtered, and evaporated to give crude bromide 8. A suspension of $\mathrm{K}_{2} \mathrm{CO}_{3}(27.68 \mathrm{mmol})$, 18-crown-6 (10.36 mmol), and 6-chloropurine $(13.81 \mathrm{mmol})$ or 2-amino-6-chloropurine $(13.81 \mathrm{mmol})$ in $\mathrm{N}, \mathrm{N}$-dimethylformamide $(100 \mathrm{~mL})$ was stirred under $\mathrm{N}_{2}$ at $85^{\circ} \mathrm{C}$ for $3 \mathrm{~h}$. To this mixture, a solution of 8 in $N, N$-dimethylformamide (DMF) $(10 \mathrm{~mL})$ was added and the reaction mixture was stirred at $55{ }^{\circ} \mathrm{C}$ for $7 \mathrm{~h}$, filtered, and evaporated. The residue was purified by silica gel column chromatography (hexanes:ethyl acetate $=1: 1$ ) to give the base condensed product 9, 10, 18, or 19 .

9-((2-O-tert-Butyldiphenylsilyloxyethylselanylmethyl)-6-chloro-9H-purin (9). Yield: 46\%; colorless syrup; $\mathrm{UV}(\mathrm{MeOH}) \lambda_{\max } 264 \mathrm{~nm} ;{ }^{1} \mathrm{H}-\mathrm{NMR}\left(400 \mathrm{MHz}, \mathrm{CDCl}_{3}\right) \delta 8.71(\mathrm{~s}, 1 \mathrm{H}), 8.17(\mathrm{~s}, 2 \mathrm{H}), 7.68-7.65(\mathrm{~m}, 4 \mathrm{H})$, 7.46-7.37 (m, 6H), $5.43(\mathrm{~s}, 2 \mathrm{H}), 3.93(\mathrm{t}, J=6 \mathrm{~Hz}, 2 \mathrm{H}), 2.88(\mathrm{t}, J=6.4 \mathrm{~Hz}, 2 \mathrm{H}), 1.05(\mathrm{~s}, 9 \mathrm{H}) ;{ }^{13} \mathrm{C}-\mathrm{NMR}$ $\left(100 \mathrm{MHz}, \mathrm{CDCl}_{3}\right) \delta 152.13,151.51,151.24,144.86,135.54,133.11,131.69,129.89,127.79,64.07,34.20$, 27.93, 26.81, 19.17; MS (ESI) $m / z$ 531.0888 (M + H) ${ }^{+}$; Anal. Calcd. for $\mathrm{C}_{24} \mathrm{H}_{27} \mathrm{ClN}_{4} \mathrm{OSeSi}$ : C, 54.39; $\mathrm{H}$, 5.14; N, 10.57. Found: C, 54.89; H, 4.99; N, 10.43 . 
9-((2-O-tert-Butyldiphenylsilyloxyethylselanyl)methyl)-6-chloro-9H-purin-2-amine (10). Yield: $45 \%$; white solid; m.p. $115-120{ }^{\circ} \mathrm{C}$; UV (MeOH) $\lambda_{\max } 310 \mathrm{~nm} ;{ }^{1} \mathrm{H}-\mathrm{NMR}\left(400 \mathrm{MHz}, \mathrm{CDCl}_{3}\right) \delta 7.81(\mathrm{~s}, 1 \mathrm{H}), 7.6-7.65$ $(\mathrm{m}, 4 \mathrm{H}), 7.46-7.37(\mathrm{~m}, 6 \mathrm{H}), 5.22(\mathrm{~s}, 2 \mathrm{H}), 3.92(\mathrm{t}, J=6.8 \mathrm{~Hz}, 2 \mathrm{H}), 2.86(\mathrm{t}, J=6.4 \mathrm{~Hz}, 2 \mathrm{H}), 1.05(\mathrm{~s}, 9 \mathrm{H}) ; \mathrm{MS}$ (ESI) $m / z 546.0995(\mathrm{M}+\mathrm{H})^{+}$; Anal. Calcd. for $\mathrm{C}_{24} \mathrm{H}_{28} \mathrm{ClN}_{5} \mathrm{OSeSi}$ C, 52.89; $\mathrm{H}, 5.18 ; \mathrm{N}, 12.85$. Found: $\mathrm{C}$, $52.99 ; \mathrm{H}, 4.98 ; \mathrm{N}, 12.45$.

9-((2-Phenyl-1, 3-dioxan-5-ylselanyl)methyl)-6-chloro-9H-purin (18). Yield: 45\%; colorless syrup; UV $(\mathrm{MeOH}) \lambda_{\max } 264 \mathrm{~nm} ;{ }^{1} \mathrm{H}-\mathrm{NMR}\left(400 \mathrm{MHz}, \mathrm{CDCl}_{3}\right) \delta 8.79(\mathrm{~s}, 1 \mathrm{H}), 8.27(\mathrm{~s}, 1 \mathrm{H}), 7.41-7.39(\mathrm{~m}, 2 \mathrm{H})$, $7.33-7.31(\mathrm{~m}, 3 \mathrm{H}), 5.46(\mathrm{~s}, 2 \mathrm{H}), 5.43(\mathrm{~s}, 1 \mathrm{H}), 4.29(\mathrm{dd}, J=4.6 \mathrm{~Hz}, 11.4 \mathrm{~Hz}, 2 \mathrm{H}), 3.78(\mathrm{t}, J=11.8 \mathrm{~Hz}, 2 \mathrm{H})$, 3.65-3.57 (m, 1H); MS (ESI) $m / z 411.0113(\mathrm{M}+\mathrm{H})^{+}$; Anal. Calcd. for $\mathrm{C}_{16} \mathrm{H}_{15} \mathrm{ClN}_{4} \mathrm{O}_{2} \mathrm{Se}: \mathrm{C}, 46.90 ; \mathrm{H}$, 3.69; N, 13.67. Found: C, 46.56; H, 3.39; N, 13.89 .

9-((2-Phenyl-1,3-dioxan-5-ylselanyl)methyl)-6-chloro-9H-purin-2-amine (19). Yield: 45\%; white solid; m.p. 164-166 ${ }^{\circ} \mathrm{C}$; UV (MeOH) $\lambda_{\max } 310 \mathrm{~nm} ;{ }^{1} \mathrm{H}-\mathrm{NMR}\left(400 \mathrm{MHz}, \mathrm{CDCl}_{3}\right) \delta 7.88(\mathrm{~s}, 1 \mathrm{H}), 7.43-7.40(\mathrm{~m}, 2 \mathrm{H})$, 7.36-7.32 (m, 3H), $5.44(\mathrm{~s}, 1 \mathrm{H}), 5.27(\mathrm{~s}, 2 \mathrm{H}), 5.24(\mathrm{~s}, 2 \mathrm{H}), 4.32(\mathrm{dd}, J=4.5$ and $11.4 \mathrm{~Hz}, 2 \mathrm{H}), 3.82-3.76$ (m, 2H), 3.69-3.63 (s, 1H); ${ }^{13} \mathrm{C}-\mathrm{NMR}\left(125 \mathrm{MHz}, \mathrm{CD}_{3} \mathrm{OD}\right) \delta 159.3,153.4,151.8,141.4,137.6,129.1,128.3$, 125.9, 125.2, 101.4 , 71.4. 35.4, 33.4; MS (FAB) $m / z$ 426.0117 (M + H) ${ }^{+}$; Anal. Calcd. for $\mathrm{C}_{16} \mathrm{H}_{16} \mathrm{ClN}_{5} \mathrm{O}_{2} \mathrm{Se}$ : C, 45.24; H, 3.80; N, 16.49. Found: C, 45.33; H, 4.10; N, 16.55 .

\subsection{General Procedure for TBDPS Removals}

To a solution of 9 or $\mathbf{1 0}(4.036 \mathrm{mmol})$ in tetrahydrofuran (THF) $(40 \mathrm{~mL})$, tetra- $n$-butylammonium fluoride (2.06 mmol, $1 \mathrm{M}$ solution in THF) was added under $\mathrm{N}_{2}$, and the reaction mixture stirred at room temperature for $1 \mathrm{~h}$ and evaporated. The residue was purified by column chromatography (hexanes:ethyl acetate $=1: 9$ ) to give $\mathbf{1 1}$ or $\mathbf{1 2}$, respectively.

2-((6-Chloro-9H-purin-9-yl)methylselanyl) ethanol (11). Yield: 92\%; white solid; m.p. $98-100{ }^{\circ} \mathrm{C}$; UV $(\mathrm{MeOH}) \lambda_{\max } 264 \mathrm{~nm} ;{ }^{1} \mathrm{H}-\mathrm{NMR}\left(400 \mathrm{MHz}, \mathrm{CDCl}_{3}\right) \delta 8.79(\mathrm{~s}, 1 \mathrm{H}), 8.32(\mathrm{~s}, 1 \mathrm{H}), 5.61(\mathrm{~s}, 2 \mathrm{H}), 4.02(\mathrm{q}$, $J=5.6 \mathrm{~Hz}, 2 \mathrm{H}), 2.88(\mathrm{t}, J=5.6 \mathrm{~Hz}, 2 \mathrm{H}), 2.65(\mathrm{t}, J=5.6 \mathrm{~Hz}, 1 \mathrm{H}) ;{ }^{13} \mathrm{C}-\mathrm{NMR}\left(100 \mathrm{MHz}, \mathrm{CDCl}_{3}\right) \delta$ 152.30, $151.72,151.69,145.47,132.03,63.41,34.54,28.28$; MS (ESI) $m / z 290.9713(\mathrm{M}+\mathrm{H})^{+}$.

2-((2-Amino-6-chloro-9H-purin-9-yl)methylselanyl) ethanol (12). Yield: $45 \%$; white solid; m.p. 150-152 ${ }^{\circ} \mathrm{C}$; $\mathrm{UV}(\mathrm{MeOH}) \lambda_{\max } 310 \mathrm{~nm} ;{ }^{1} \mathrm{H}-\mathrm{NMR}\left(400 \mathrm{MHz}, \mathrm{DMSO}-d_{6}\right) \delta 8.22$ (s, 1H), 6.95 (br s, 2H, exchangeable), $5.35(\mathrm{~s}, 2 \mathrm{H}), 3.59(\mathrm{t}, J=6.4 \mathrm{~Hz}, 2 \mathrm{H}), 2.83(\mathrm{t}, J=6.8 \mathrm{~Hz}, 2 \mathrm{H}) ;{ }^{13} \mathrm{C}-\mathrm{NMR}\left(100 \mathrm{MHz}, \mathrm{DMSO}-d_{6}\right) \delta 159.8$, 153.6, 149.5, 142.7, 123.4, 61.4, 33.8, 27.7; MS (ESI) $m / z 307.9807(\mathrm{M}+\mathrm{H})^{+}$.

\subsection{General Procedure for the 1,3-Benzylidene Removals}

To a solution of 18 or $19(7.06 \mathrm{mmol})$ in $\mathrm{MeOH}(20 \mathrm{~mL})$, iodine $(0.2 \mathrm{~mL}, 0.1 \mathrm{M}$ solution in $\mathrm{MeOH})$ was added and the reaction mixture was heated at $60^{\circ} \mathrm{C}$ for $4 \mathrm{~h}$. Then, the reaction mixture was quenched with few drops of aqueous sodium thiosulfate and evaporated. The residue was purified by silica gel column chromatography $\left(\mathrm{CH}_{2} \mathrm{Cl}_{2}: \mathrm{MeOH}=24: 1\right)$ to give 20 or 21, respectively.

2-((6-Chloro-9H-purin-9-yl)methylselanyl) propane-1, 3-diol (20). Yield: 88\%; white solid; m.p. $140-143{ }^{\circ} \mathrm{C}$; $\mathrm{UV}(\mathrm{MeOH}) \lambda_{\max } 263 \mathrm{~nm} ;{ }^{1} \mathrm{H}-\mathrm{NMR}\left(400 \mathrm{MHz}, \mathrm{CD}_{3} \mathrm{OD}\right) \delta 8.75(\mathrm{~s}, 1 \mathrm{H}), 8.69(\mathrm{~s}, 1 \mathrm{H}), 5.68(\mathrm{~s}, 2 \mathrm{H}), 3.79$ (s, 2H), 3.77 (s, 2H), $3.27(\mathrm{~s}, 1 \mathrm{H}) ;{ }^{13} \mathrm{C}-\mathrm{NMR}\left(100 \mathrm{MHz}, \mathrm{CD}_{3} \mathrm{OD}\right) \delta 153.89,153.78,152.11,148.97,133.23$, 64.54, 49.63, 35.80; MS (FAB) $m / z 326.1516(\mathrm{M}+\mathrm{H})^{+}$.

2-((2-Amino-6-chloro-9H-purin-9-yl)methylselanyl) propane-1,3-diol (21). Yield: 88\%; white solid; m.p. $160-162{ }^{\circ} \mathrm{C}$; UV (MeOH) $\lambda_{\max } 310 \mathrm{~nm} ;{ }^{1} \mathrm{H}-\mathrm{NMR}\left(400 \mathrm{MHz}, \mathrm{CD}_{3} \mathrm{OD}\right) \delta 8.18(\mathrm{~s}, 1 \mathrm{H}), 5.45(\mathrm{~s}, 2 \mathrm{H}), 3.85-3.76$ (m, 4H), 3.3-3.33 (m, 1H); ${ }^{13} \mathrm{C}-\mathrm{NMR}\left(100 \mathrm{MHz}, \mathrm{CD}_{3} \mathrm{OD}+\mathrm{CDCl}_{3}\right) \delta$ 162.1, 155.5, 152.3, 144.7, 125.6, 71.8, 64.4, 48.8, 35.0; MS (ESI) $m / z 337.9915(\mathrm{M}+\mathrm{H})^{+}$; Anal. Calcd. for $\mathrm{C}_{9} \mathrm{H}_{12} \mathrm{ClN}_{5} \mathrm{O}_{2} \mathrm{Se}: \mathrm{C}, 32.11 ; \mathrm{H}, 3.59 ; \mathrm{N}$, 20.80. Found: C, 32.01; H, 3.91; N, 20.56. 


\subsection{Conversion of 6-Chloro Derivatives to 6-Keto Derivatives}

A solution of 6-chloro derivative 11, 12, 20, or 21 (0.358 $\mathrm{mmol}), 2$-mercaptoethanol (1.297 mmol) and $\mathrm{NaOMe}(1.797 \mathrm{mmol})$ in methanol $(15 \mathrm{~mL})$ was refluxed for 4 days at $75^{\circ} \mathrm{C}$. After completion of the reaction, the reaction mixture was cooled and neutralized with acetic acid. The solvent was removed under reduced pressure and the residue was chromatographed $\left(\mathrm{CH}_{2} \mathrm{Cl}_{2}: \mathrm{MeOH}=7: 1\right)$ to give the 6-keto derivative $3 \mathbf{a}, \mathbf{4 a}, \mathbf{3 d}$, or $4 \mathbf{d}$.

9-((2-Hydroxyethylselanyl)methyl)-1H-purin-6-(9H)-one (3a). Yield: 80\%; white solid; m.p. $225-22{ }^{\circ} \mathrm{C}$; $\mathrm{UV}(\mathrm{MeOH}) \lambda_{\max }, 248 \mathrm{~nm} ;{ }^{1} \mathrm{H}-\mathrm{NMR}\left(400 \mathrm{MHz}, \mathrm{DMSO}-d_{6}\right) \delta 8.16(\mathrm{~s}, 1 \mathrm{H}), 8.06(\mathrm{~s}, 1 \mathrm{H}), 5.44$ (s, $\left.2 \mathrm{H}\right), 4.89$ (br s, 1H, exchangeable), 3.58-3.56 (m, 2H), $2.81(\mathrm{t}, J=6.8 \mathrm{~Hz}, 2 \mathrm{H}) ;{ }^{13} \mathrm{C}-\mathrm{NMR}\left(100 \mathrm{MHz}, \mathrm{DMSO}-d_{6}\right)$ $\delta$ 156.64, 148.03, 145.87, 139.96, 124.13, 61.29, 33.95, 27.55; MS (ESI) $m / z$ 275.0041 (M + H) ${ }^{+}$; Anal. Calcd. for $\mathrm{C}_{8} \mathrm{H}_{10} \mathrm{~N}_{4} \mathrm{O}_{2} \mathrm{Se}: \mathrm{C}, 35.18 ; \mathrm{H}, 3.69 ; \mathrm{N}, 20.51$. Found: C, 35.19; H, 3.56; N, 20.11.

9-((2-Hydroxyethylselanyl)methyl)-2-amino-1H purin-6(9H)-one (4a) [12]. Yield: 94\%; white solid: m.p. 266-268 ${ }^{\circ} \mathrm{C}$; UV (MeOH) $\lambda_{\max } 259 \mathrm{~nm} ;{ }^{1} \mathrm{H}-\mathrm{NMR}\left(400 \mathrm{MHz}, \mathrm{DMSO}-d_{6}\right) \delta 10.60$ (br s, 1H, exchangeable with $\left.\mathrm{D}_{2} \mathrm{O}\right), 7.78(\mathrm{~s}, 1 \mathrm{H}), 6.49$ (br s, 2H), $5.23(\mathrm{~s}, 2 \mathrm{H}), 4.86(\mathrm{t}, J=5.3 \mathrm{~Hz}, 1 \mathrm{H}), 3.58(\mathrm{q}, J=6.5 \mathrm{~Hz}, 2 \mathrm{H}), 2.79$ $(\mathrm{t}, J=6.8 \mathrm{~Hz}, 2 \mathrm{H}) ;{ }^{13} \mathrm{C}-\mathrm{NMR}\left(100 \mathrm{MHz}, \mathrm{DMSO}-d_{6}\right) \delta 156.7,153.7,150.9,137.1,116.6,61.4,33.4,27.3$; MS (ESI) $m / z 290.0152(\mathrm{M}+\mathrm{H})^{+}$; Anal. Calcd. for $\mathrm{C}_{8} \mathrm{H}_{11} \mathrm{~N}_{5} \mathrm{O}_{2}$ Se: C, 33.34; $\mathrm{H}, 3.85 ; \mathrm{N}, 24.30$. Found: C, 33.14; H, 4.15; N, 24.01 .

9-((1,3-Dihydroxypropan-2-ylselanyl)methyl)-1H purin-6(9H)-one (3d). Yield: 85\%; white solid; m.p. 189-182 ${ }^{\circ} \mathrm{C}$; UV (MeOH) $\lambda_{\max } 247 \mathrm{~nm} ;{ }^{1} \mathrm{H}-\mathrm{NMR}\left(400 \mathrm{MHz}, \mathrm{DMSO}-d_{6}\right) \delta 8.17(\mathrm{~s}, 1 \mathrm{H}), 8.06(\mathrm{~s}, 1 \mathrm{H}), 5.46(\mathrm{~s}$, $2 \mathrm{H}), 4.84$ (br s, $2 \mathrm{H}$, exchangeable), 3.65-3.56 (m, 4H), 3.21-3.17 (m, 1H); ${ }^{13} \mathrm{C}-\mathrm{NMR}\left(100 \mathrm{MHz}, \mathrm{DMSO}-d_{6}\right)$ $\delta$ 156.68, 148.01, 145.84, 139.93, 124.06, 61.49, 47.30, 33.23; MS (ESI) $m / z$ 305.0142 (M + H) ${ }^{+}$; Anal. Calcd. for $\mathrm{C}_{9} \mathrm{H}_{12} \mathrm{~N}_{4} \mathrm{O}_{3}$ Se: C, 35.66; H, 3.99; N, 18.48. Found: C, 35.26; H, 4.13; N, 18.08 .

9-((1,3-Dihydroxypropan-2-ylselanyl)methyl)-2-amino-1H-purin-6(9H)-one (4d) [12]. Yield: 70\%; white solid; m.p. 204-207 ${ }^{\circ} \mathrm{C}$; UV (MeOH) $\lambda_{\max } 258 \mathrm{~nm} ;{ }^{1} \mathrm{H}-\mathrm{NMR}\left(400 \mathrm{MHz}, \mathrm{DMSO}-d_{6}\right) \delta 10.69$ (br s, $1 \mathrm{H}$, exchangeable with $\left.\mathrm{D}_{2} \mathrm{O}\right), 7.78(\mathrm{~s}, 1 \mathrm{H}), 6.59\left(\mathrm{~s}, 2 \mathrm{H}\right.$, exchangeable with $\left.\mathrm{D}_{2} \mathrm{O}\right), 5.5(\mathrm{~s}, 2 \mathrm{H}), 4.84(\mathrm{t}, \mathrm{J}=5.3 \mathrm{~Hz}$, $2 \mathrm{H}$, exchangeable with $\left.\mathrm{D}_{2} \mathrm{O}\right), 3.69-3.64(\mathrm{~m}, 2 \mathrm{H}), 3.62-3.56\left(\mathrm{~m}, 2 \mathrm{H}\right.$, exchangeable with $\left.\mathrm{D}_{2} \mathrm{O}\right), 3.21-3.16$ $(\mathrm{m}, 1 \mathrm{H}) ;{ }^{13} \mathrm{C}-\mathrm{NMR}\left(100 \mathrm{MHz}, \mathrm{DMSO}-d_{6}\right) \delta 156.8,153.8,150.9,137.0,116.6,61.6,47.0,32.8 ; \mathrm{MS}$ (ESI) $\mathrm{m} / z$ 320.0254 $(\mathrm{M}+\mathrm{H})^{+}$; Anal. Calcd. for $\mathrm{C}_{9} \mathrm{H}_{13} \mathrm{~N}_{5} \mathrm{O}_{3}$ Se: $\mathrm{C}, 33.97 ; \mathrm{H}, 4.12 ; \mathrm{N}, 22.01$. Found: $\mathrm{C}, 34.12 ; \mathrm{H}, 4.42$; $\mathrm{N}, 22.37$.

\subsection{Conversion of 6-Chloro Derivatives to $N^{6}$-Methylamino Derivatives}

A solution of 6-chloro derivative 11, 12, 20, or 21 (0.342 mmol) and methylamine (10 $\mathrm{mL}, 40 \%$ aqueous solution) in methanol $(10 \mathrm{~mL})$ was heated at $85^{\circ} \mathrm{C}$ for $48 \mathrm{~h}$ in a steel bomb. After completion of the reaction, the solvent was removed and the residue was purified by silica gel column chromatography $\left(\mathrm{CH}_{2} \mathrm{Cl}_{2}: \mathrm{MeOH}=20: 1\right)$ to give the $N^{6}$-methylamino derivative $3 \mathbf{b}, \mathbf{4 b}, \mathbf{3 e}$, or $4 \mathbf{e}$.

2-((6-(Methylamino)-9H-purin-9-yl)methylselanyl) ethanol (3b). Yield: 70\%; white solid; m.p. 171-173 ${ }^{\circ} \mathrm{C}$; UV (MeOH) $\lambda_{\max } 266$ nm; ${ }^{1} \mathrm{H}-\mathrm{NMR}\left(400 \mathrm{MHz}, \mathrm{CD}_{3} \mathrm{OD}\right) \delta 8.26$ (s, 1H), 8.17 (s, 1H), 5.49 (s, $\left.2 \mathrm{H}\right), 3.73$ $(\mathrm{t}, J=6.6 \mathrm{~Hz}, 2 \mathrm{H}), 3.10\left(\right.$ broad s, 3H) $2.84(\mathrm{t}, J=6.6 \mathrm{~Hz}, 2 \mathrm{H}) ;{ }^{13} \mathrm{C}-\mathrm{NMR}\left(100 \mathrm{MHz}, \mathrm{CD}_{3} \mathrm{OD}\right) \delta 157.58$, 154.69, 150.18, 142.64, 121.46, 64.11, 35.66, 28.88; MS (ESI) $m / z 288.0363(\mathrm{M}+\mathrm{H})^{+}$; Anal. Calcd. for $\mathrm{C}_{9} \mathrm{H}_{13} \mathrm{~N}_{5} \mathrm{OSe}: \mathrm{C}, 37.77 ; \mathrm{H}, 4.58 ; \mathrm{N}, 24.47$. Found: C, 37.78; H, 4.55; N, 24.31.

2-((2-Amino-6-(methylamino)-9H-purin-9-yl)methylselanyl) ethanol (4b). Yield: 85\%; white solid; m.p. 183-185 ${ }^{\circ} \mathrm{C}$; UV (MeOH) $\lambda_{\max } 282 \mathrm{~nm} ;{ }^{1} \mathrm{H}-\mathrm{NMR}\left(400 \mathrm{MHz}, \mathrm{CD}_{3} \mathrm{OD}\right) \delta 7.81(\mathrm{~s}, 1 \mathrm{H}), 5.35$ (s, $\left.2 \mathrm{H}\right), 3.75$ $(\mathrm{t}, J=6.7 \mathrm{~Hz}, 2 \mathrm{H}), 3.04\left(\right.$ broad s, 3H) $2.85(\mathrm{t}, J=6.6 \mathrm{~Hz}, 2 \mathrm{H}) ;{ }^{13} \mathrm{C}-\mathrm{NMR}\left(75 \mathrm{MHz}, \mathrm{CD}_{3} \mathrm{OD}\right) \delta 162.91$, 158.07, 139.54, 115.59, 64.28, 64.28, 35.28, 31.54, 28.58; MS (ESI) $m / z$ 303.0472 (M + H) ${ }^{+}$; Anal. Calcd. for $\mathrm{C}_{9} \mathrm{H}_{14} \mathrm{~N}_{6} \mathrm{OSe}: \mathrm{C}, 35.89 ; \mathrm{H}, 4.69 ; \mathrm{N}, 27.90$. Found: C, 36.18; H, 4.32; N, 28.01.

2-((6-(Methylamino)-9H-purin-9-yl)methylselanyl)propane-1,3-diol (3e). Yield: 50\%; white solid; m.p. 180-183 ${ }^{\circ} \mathrm{C}$; UV (MeOH) $\lambda_{\max } 266 \mathrm{~nm} ;{ }^{1} \mathrm{H}-\mathrm{NMR}\left(400 \mathrm{MHz}, \mathrm{DMSO}-d_{6}\right) \delta 8.24(\mathrm{~s}, 1 \mathrm{H}), 8.22(\mathrm{~s}, 1 \mathrm{H}), 7.69$ 
(br s, 1H, exchangeable), $5.48(\mathrm{~s}, 2 \mathrm{H}), 4.84(\mathrm{t}, J=5.1 \mathrm{~Hz}, 2 \mathrm{H}$, exchangeable), 3.67-3.56 (m, 4H), 3.25-3.21 (m, 1H), 2.96 (br s, 3H); ${ }^{13}$ C-NMR (75 MHz, DMSO-d $) \delta 154.90,152.56,148.14,140.19,119.20,61.55$, 47.26, 33.03, 27.01; MS (ESI) $m / z$ 318.0469 (M + H) ${ }^{+}$; Anal. Calcd. for $\mathrm{C}_{10} \mathrm{H}_{15} \mathrm{~N}_{5} \mathrm{O}_{2} \mathrm{Se}: \mathrm{C}, 37.98$; $\mathrm{H}, 4.78$; $\mathrm{N}, 22.15$. Found: C, 37.99; $\mathrm{H}, 4.36 ; \mathrm{N}, 22.01$.

2-((2-Amino-6-(methylamio)-9H-purin-9-yl)methylselanyl) propane-1,3-diol (4e). Yield: 50\%; white solid; m.p. $140-143{ }^{\circ} \mathrm{C}$; UV (MeOH) $\lambda_{\max } 282 \mathrm{~nm} ;{ }^{1} \mathrm{H}-\mathrm{NMR}\left(400 \mathrm{MHz}, \mathrm{DMSO}-d_{6}\right) \delta 7.77$ (s, $\left.1 \mathrm{H}\right), 7.16$ (br s, $1 \mathrm{H}$, exchangeable), $5.88(\mathrm{~s}, 2 \mathrm{H}$, exchangeable), $5.28(\mathrm{~s}, 2 \mathrm{H}), 4.82(\mathrm{t}, \mathrm{J}=5.2 \mathrm{~Hz}, 2 \mathrm{H}$, exchangeable), 3.70-3.65 $(\mathrm{m}, 2 \mathrm{H}), 3.63-3.57(\mathrm{~m}, 2 \mathrm{H}), 3.21-3.16(\mathrm{~m}, 1 \mathrm{H}), 2.89$ (br s, 3H); ${ }^{13} \mathrm{C}-\mathrm{NMR}\left(100 \mathrm{MHz}, \mathrm{DMSO}-d_{6}\right) \delta 160.28$, 155.38, 136.57, 113.43, 105.24, 61.67, 46.88, 32.61, 26.90, 26.85; MS (ESI) $m / z 333.0573(\mathrm{M}+\mathrm{H})^{+}$; Anal. Calcd. for $\mathrm{C}_{10} \mathrm{H}_{16} \mathrm{~N}_{6} \mathrm{O}_{2}$ Se: $\mathrm{C}, 36.26 ; \mathrm{H}, 4.87 ; \mathrm{N}, 25.37$. Found: C, 36.56; $\mathrm{H}, 443 ; \mathrm{N}, 25.08$.

\subsection{Conversion of 6-Chloro Derivatives to $N^{6}$-Amino Derivatives}

6-Chloro derivative 11, 12, 20, or $21(0.342 \mathrm{mmol})$ and $\mathrm{NH}_{3} / \mathrm{t}$-butanol $(10 \mathrm{~mL})$ were taken in a steel bomb and heated at $85^{\circ} \mathrm{C}$ for $12 \mathrm{~h}$. The solvent was removed and the residue was purified by silica gel column chromatography $\left(\mathrm{CH}_{2} \mathrm{Cl}_{2}: \mathrm{MeOH}=24: 1\right)$ to give $N^{6}$-amino derivative $\mathbf{3 c}, \mathbf{4 c}, \mathbf{3 f}, \mathbf{4 f}$, or $\mathbf{4 g}$.

2-((6-Amino-9H-purin-9-yl)methylselanyl)ethanol (3c). Yield: 95\%; white solid; m.p. 175-177 ${ }^{\circ} \mathrm{C}$; UV $(\mathrm{MeOH}) \lambda_{\max } 260 \mathrm{~nm} ;{ }^{1} \mathrm{H}-\mathrm{NMR}\left(400 \mathrm{MHz}, \mathrm{CD}_{3} \mathrm{OD}\right) \delta 8.25(\mathrm{~s}, 1 \mathrm{H}), 8.23(\mathrm{~s}, 1 \mathrm{H}), 5.52(\mathrm{~s}, 2 \mathrm{H}), 3.74(\mathrm{t}$, $J=6.4 \mathrm{~Hz}, 2 \mathrm{H}), 2.86(\mathrm{t}, J=6.4 \mathrm{~Hz}, 2 \mathrm{H}) ;{ }^{13} \mathrm{C}-\mathrm{NMR}\left(100 \mathrm{MHz}, \mathrm{CD}_{3} \mathrm{OD}\right) \delta 157.41,153.94,150.52,142.52$, 120.17, 63.35, 34.95, 28.16; MS (ESI) $m / z$ 274.0202 (M + H) ${ }^{+}$; Anal. Calcd. for $\mathrm{C}_{8} \mathrm{H}_{11} \mathrm{~N}_{5} \mathrm{OSe}: \mathrm{C}, 35.30 ; \mathrm{H}$, 4.07; N, 25.73. Found: C, 35.20; H, 4.47; N, 25.43.

2-((2,6-Diamino-9H-purin-9-yl)methylselanyl) ethanol (4c). Yield: 70\%; white solid; m.p. 84-86 ${ }^{\circ} \mathrm{C} ; \mathrm{UV}$ $(\mathrm{MeOH}) \lambda_{\max } 281 \mathrm{~nm} ;{ }^{1} \mathrm{H}-\mathrm{NMR}\left(400 \mathrm{MHz}, \mathrm{DMSO}-d_{6}\right) \delta 7.80(\mathrm{~s}, 1 \mathrm{H}), 6.73$ (s, 2H, exchangeable), 5.86 (s, 2H, exchangeable), $5.28(\mathrm{~s}, 2 \mathrm{H}), 4.89(\mathrm{t}, J=5.3 \mathrm{~Hz}, 1 \mathrm{H}$, exchangeable), $3.60(\mathrm{q}, J=6.3 \mathrm{~Hz}, 2 \mathrm{H}), 2.81$ $(\mathrm{t}, J=6.7 \mathrm{~Hz}, 2 \mathrm{H}) ;{ }^{13} \mathrm{C}-\mathrm{NMR}\left(75 \mathrm{MHz}, \mathrm{DMSO}-d_{6}\right) \delta 160.32,156.07,151.42,136.99,113.11,61.46,33.28$, 27.22; MS (ESI) $m / z 289.0314(\mathrm{M}+\mathrm{H})^{+}$; Anal. Calcd. for $\mathrm{C}_{8} \mathrm{H}_{12} \mathrm{~N}_{6} \mathrm{OSe}$ C, 33.46; H, 4.21; N, 29.26. Found: C, 33.20; H, 4.41; N, 29.43.

2-((6-Amino-9H-purin-9-yl)methylselanyl)propane-1,3-diol (3f). Yield: 80\%; white solid; m.p. $186-188{ }^{\circ} \mathrm{C}$; UV (MeOH) $\lambda_{\max } 260 \mathrm{~nm} ;{ }^{1} \mathrm{H}-\mathrm{NMR}\left(400 \mathrm{MHz}, \mathrm{DMSO}-d_{6}\right) \delta 8.23(\mathrm{~s}, 1 \mathrm{H}), 8.16(\mathrm{~s}, 1 \mathrm{H}), 7.23(\mathrm{~s}, 2 \mathrm{H}$, exchangeable), $5.47(\mathrm{~s}, 2 \mathrm{H}), 4.85(\mathrm{t}, J=5.1 \mathrm{~Hz}, 2 \mathrm{H}$, exchangeable), 3.67-3.57 (m, 4H), 3.24-3.21 (m, 1H); ${ }^{13} \mathrm{C}-\mathrm{NMR}\left(100 \mathrm{MHz}, \mathrm{DMSO}-d_{6}\right) \delta 155.93,152.53,149.11,140.47,118.72,61.57,47.24,32.96$; MS (ESI) $m / z$ 304.0292 $(\mathrm{M}+\mathrm{H})^{+}$; Anal. Calcd. for $\mathrm{C}_{9} \mathrm{H}_{13} \mathrm{~N}_{5} \mathrm{O}_{2} \mathrm{Se}: \mathrm{C}, 35.77 ; \mathrm{H}, 4.34 ; \mathrm{N}, 23.18$. Found: $\mathrm{C}, 35.89 ; \mathrm{H}$, $4.12 ; \mathrm{N}, 23.02$.

2-((2,6-Diamino-9H-purin-9-yl)methylselanyl)propane-1,3-diol (4f). Yield: 75\%; white solid; m.p. $193-196{ }^{\circ} \mathrm{C}$; UV (MeOH) $\lambda_{\max } 282 \mathrm{~nm} ;{ }^{1} \mathrm{H}-\mathrm{NMR}\left(400 \mathrm{MHz}, \mathrm{DMSO}-d_{6}\right) \delta 7.79$ (s, 1H), 6.67 (s, 2H, exchangeable), $5.81(\mathrm{~d}, J=2.8 \mathrm{~Hz}, 2 \mathrm{H}$, exchangeable), $5.28(\mathrm{~s}, 2 \mathrm{H}), 4.84(\mathrm{t}, J=5.1 \mathrm{~Hz}, 1 \mathrm{H}$, exchangeable), 3.71-3.66 (m, $2 \mathrm{H}), 3.63-3.57(\mathrm{~m}, 2 \mathrm{H}), 3.29\left(\mathrm{~s}, 1 \mathrm{H}\right.$, exchangeable), 3.23-3.16 (m, 1H); ${ }^{13} \mathrm{C}-\mathrm{NMR}\left(100 \mathrm{MHz}, \mathrm{DMSO}-d_{6}\right) \delta$ 160.20, 156.03, 151.36, 136.98, 113.09, 61.66, 61.55, 46.84, 32.61; MS (ESI) $m / z$ 319.0414 (M + H) ${ }^{+}$; Anal. Calcd. for $\mathrm{C}_{9} \mathrm{H}_{14} \mathrm{~N}_{6} \mathrm{O}_{2}$ Se: C, 34.08; H, 4.45; N, 26.49. Found: C, 34.48; H, 4.17; N, 26.83.

2-((2-Amino-6-(cyclopropylamino)-9H-purin-9-yl)methylselanyl)propane-1,3-diol (4g). To a solution of 44 $(100 \mathrm{mg}, 0.296 \mathrm{mmol})$ in ethanol $(10 \mathrm{~mL})$ in a steel bomb, cyclopropylamine $(0.103 \mathrm{~mL}, 1.486 \mathrm{mmol})$ and triethylamine $(0.272 \mathrm{~mL}, 1.950 \mathrm{mmol})$ were added and the mixture was heated at $100{ }^{\circ} \mathrm{C}$ for $48 \mathrm{~h}$. After completion of the reaction, the solvent was removed and the residue was purified by silica gel chromatography $\left(\mathrm{CH}_{2} \mathrm{Cl}_{2}: \mathrm{MeOH}=20: 1\right.$ to give $4 \mathrm{~d}(52 \mathrm{mg}, 55 \%)$ as a white solid: m.p. $140-143{ }^{\circ} \mathrm{C}$; UV $(\mathrm{MeOH}) \lambda_{\max } 285 \mathrm{~nm} ;{ }^{1} \mathrm{H}-\mathrm{NMR}\left(400 \mathrm{MHz}, \mathrm{DMSO}-d_{6}\right) \delta 7.79$ (s, 1H), 7.29 (br s, 1H, exchangeable), 5.88 (s, 2H, exchangeable), $5.29(\mathrm{~s}, 2 \mathrm{H}), 4.84(\mathrm{t}, J=5.2 \mathrm{~Hz}, 2 \mathrm{H}$, exchangeable), 3.71-3.66 (m, 2H), 3.63-3.57 $(\mathrm{m}, 2 \mathrm{H}), 3.22-3.19(\mathrm{~m}, 1 \mathrm{H}), 3.03$ (br s, 1H), 0.68-0.62 (m, 2H), 0.59-0.58 (m, 2H); ${ }^{13} \mathrm{C}-\mathrm{NMR}(100 \mathrm{MHz}$, DMSO- $\left.d_{6}\right) \delta 160.19,155.81,150.94,136.73,113.35,69.68,61.63,46.91,32.66,23.86,6.44 ;$ MS (ESI) $m / z$ 
359.0731 $(\mathrm{M}+\mathrm{H})^{+}$; Anal. Calcd. for $\mathrm{C}_{12} \mathrm{H}_{18} \mathrm{~N}_{6} \mathrm{O}_{2}$ Se: $\mathrm{C}, 40.34 ; \mathrm{H}, 5.08 ; \mathrm{N}, 23.52$. Found: $\mathrm{C}, 40.14 ; \mathrm{H}$, $5.17 ; \mathrm{N}, 23.12$.

\subsection{Antiviral Activity and Cytotoxicity Assays}

Antiviral activity was measured using a standard cytopathic (CPE) inhibition assay as described before [13]. Briefly, Vero cells in stationary phase were infected with the virus at a multiplicity of infection of $2-4$ CCID50 (50\% cell culture inhibitory dose) per each well of 96-well plates. After $2 \mathrm{~h}$ of adsorption at $37{ }^{\circ} \mathrm{C}$, the liquid was aspirated and $100 \mu \mathrm{L}$ of Dulbeco's modified eagle's media (DMEM) $/ 2 \%$ fetal bovine serum (FBS) containing a compound was applied to each well in duplicate for each concentration and further incubated for 3 days. Antiviral activity was measured by MTT assay and expressed as the $\mathrm{EC}_{50}$. Cytocidal assay was performed as a control experiment for the antiviral assay. It was carried out simultaneously with the antiviral assay described above using mock instead of virus for infection, and cell viability was measured by MTT assay. The concentration of the compound responsible for $50 \%$ reduction of cell growth was calculated and expressed as $\mathrm{CC}_{50}$.

\section{Conclusions}

We have synthesized various acyclic seleno-purine nucleosides $\mathbf{3 a}-\mathbf{f}$ and $\mathbf{4 a -} \mathbf{g}$, and evaluated them for anti-herpetic activity. The key diselenides $\mathbf{6}$ and $\mathbf{1 6}$ were synthesized by treating bromide 5 and mesylate 15 with selenium powder and hydrazine hydrate in aqueous $\mathrm{KOH}$ solution, respectively. The glycosyl donors 8 and 17 were synthesized by treating diselenides 7 and 16 with $\mathrm{NaBH}_{4}$ followed by trapping with methylene bromide, and then condensed with 6-chloropurine or 2-amino-6-chloropurine anion in a $\mathrm{S}_{\mathrm{N}} 2$ manner. Among the compounds tested, seleno-acyclovir (4a) showed the most potent anti-HSV-1 and HSV-2 activities, while the seleno-ganciclovir analogue $4 \mathbf{e}$ exhibited the most potent anti-HCMV activity. It seems that 2,6-diaminopurine nucleosides might be converted to seleno-acyclovir (4a) and seleno-ganciclovir (4d) by cellular nucleoside deaminases, serving as prodrugs of $4 \mathbf{a}$ and $\mathbf{4 d}$. Although we could not discover more potent compounds than the reference compounds, acyclovir (1) or ganciclovir (2), it is expected that these synthesized nucleosides can be a new template for the design of novel acyclic nucleoside analogues.

Acknowledgments: This work was supported by the grants from Mid-Career Research Program (370C-20160046) of National Research Foundation (NRF), Korea. Antiviral assay by Chong-Kyo Lee (KRICT, Korea) is greatly appreciated.

Author Contributions: L.S.J. conceived and designed the experiments; P.K.S. and T.U. performed the experiments; P.K.S and L.S.J. analyzed the data; J.Y., G.K., S.Q., and, S.D.N. contributed reagents/materials/analysis tools; L.S.J. wrote the paper. All the authors contributed in writing and proofreading the manuscript.

Conflicts of Interest: The authors declare no conflict of interest.

\section{References}

1. Herdewijn, P. (Ed.) Modified Nucleosides in Biochemistry, Biotechnology and Medicine; Wiley-VCH: Weinheim, Germany, 2008; pp. 1-658.

2. Freeman, S.; Gardiner, J.M. Acyclic nucleosides as antiviral compounds. Mol. Biotechnol. 1996, 5, $125-137$. [CrossRef] [PubMed]

3. Elion, G.B.; Furman, P.A.; Fyfe, J.A.; de Miranda, P.; Beauchamp, L.; Schaeffer, H.J. Selectivity of action of an antiherpetic agent, 9-(2-hydroxyethoxymethyl)guanine. Proc. Natl. Acad. Sci. USA 1977, 74, 5716-5720. [CrossRef] [PubMed]

4. Schaeffer, H.J.; Beauchamp, L.; de Miranda, P.; Elion, G.B.; Bauer, D.J.; Collins, P. 9-(2-Hydroxyethoxymethyl)guanine activity against viruses of the herpes group. Nature 1978, 272, 583-585. [CrossRef] [PubMed]

5. Field, A.K.; Davies, M.E.; DeWitt, C.; Perry, V.; Liou, R.; Germershausen, J.; Karkas, J.D.; Ashton, W.T.; Johnson, D.B.R.; Tolman, R.L. 9-\{[2-Hydroxy-l-(hydroxymethyl)ethoxy]methyl\}guanine: A selective inhibitor of herpes group virus replication. Proc. Natl. Acad. Sci. USA 1983, 80, 4139-4143. [CrossRef] [PubMed]

6. Laskin, O.L.; Stahl-Bayliss, C.M.; Kalman, C.M.; Rosecan, L.R. Use of ganciclovir to treat serious cytomegalovirus infections in patients with AIDS. J. Infect. Dis. 1987, 155, 323-327. [CrossRef] [PubMed] 
7. Reardon, J.E.; Spector, T. Herpes simplex virus type 1 DNA polymerase. Mechanism of inhibition by acyclovir triphosphate. J. Biol. Chem. 1989, 264, 7405-7411.

8. Reardon, J.E. Herpes simplex virus type 1 and human DNA polymerase interactions with $2^{\prime}$-deoxyguanosine 5 -triphosphate analogues. Kinetics of incorporation into DNA and induction of inhibition. J. Biol. Chem. 1989, 264, 19039-19044. [PubMed]

9. De Clercq, E. Antivirals and antiviral strategies. Nat. Rev. Microbiol. 2004, 2, 704-720. [CrossRef] [PubMed]

10. Dos Santos Mde, F.; Dos Santos, O.F.; Boim, M.A.; Razvickas, C.V.; de Moura, L.A.; Ajzen, H.; Schor, N. Nephrotoxicity of acyclovir and ganciclovir in rats: Evaluation of glomerular hemodynamics. J. Am. Soc. Nephrol. 1997, 8, 361-367. [PubMed]

11. Starafeld, L.; Chou, S. Antiviral drug resistance: Mechanisms and clinical implications. Infect. Dis. Clin. N. Am. 2010, 24, 413-437. [CrossRef] [PubMed]

12. Sahu, P.K.; Umme, T.; Yu, J.; Nayak, A.; Kim, G.; Noh, M.; Lee, J.-Y.; Kim, D.-D.; Jeong, L.S. Selenoacyclovir and selenoganciclovir: Discovery of a new template for antiviral agents. J. Med. Chem. 2015, 58, 8734-8738. [CrossRef] [PubMed]

13. Paquette, L.A.; Dong, S. Stereoselective synthesis of $\beta$-anomeric 4 -thiaspirocyclic ribonucleosides carrying the full complement of RNA-level hydroxyl substitution. J. Organ. Chem. 2005, 70, 5655-5664. [CrossRef] [PubMed]

14. Jeong, L.S.; Kim, H.O.; Moon, H.R.; Hong, J.H.; Yoo, S.J.; Choi, W.J.; Chun, M.W.; Lee, C.-K. Syntheses and structure-activity relationships of novel apio and thioapio dideoxydidehydronucleosides as anti-HCMV agents. J. Med. Chem. 2001, 44, 806-813. [CrossRef]

15. Yu, J.; Sahu, P.K.; Kim, G.; Qu, S.; Choi, Y.; Song, J.; Lee, S.K.; Noh, M.; Park, S.; Jeong, L.S. Design, synthesis and cellular metabolism study of $4^{\prime}$-selenonucleosides. Future Med. Chem. 2015, 7, 1643-1655. [CrossRef] [PubMed]

Sample Availability: Samples of the compounds are not available from the authors.

(C) 2017 by the authors. Licensee MDPI, Basel, Switzerland. This article is an open access article distributed under the terms and conditions of the Creative Commons Attribution (CC BY) license (http://creativecommons.org/licenses/by/4.0/). 